\title{
Flavonoids: Molecular Mechanism Behind Natural Chemoprotective Behavior-A Mini Review
}

\author{
Deepshikha Gupta $^{1}$ (D), Eksha Guliani ${ }^{2}$ (D) \\ 1 Amity Institute of Applied Sciences, Amity University Uttar Pradesh, Noida-201301, India; dgupta2@amity.edu (D.G.); \\ 2 Amity Institute of Applied Sciences, Amity University Uttar Pradesh, Noida-201301, India; eksha.g174@gmail.com \\ (E.G.); \\ * Correspondence: dgupta2@amity.edu (D.G.);
}

Scopus Author ID 56754572800

Received: 2.08.2021; Revised: 20.09.2021; Accepted: 22.09.2021; Published: 2.11.2021

\begin{abstract}
The given review summarizes the various molecular mechanisms responsible for the metabolic action of flavonoids as anticancer agents. Various types of flavonoids have proven to show biological \& pharmacological activities like anti-inflammatory, antimicrobial, antioxidant, anticancer, anti-allergic, and antidiarrheal activities. The chemoprotective nature of flavonoids is also discussed due to their ability to inhibit topoisomerase enzymes at various stages of cancer, such as tumor initiation, promotion, and progression. The various biomolecular activities which are responsible for their role as the chemopreventive agent may be due to their antioxidative effect, anti-angiogenic properties, induction of protective enzymes, inhibitory action on the cell-like protein kinase activity inhibition, spreading of tumor cells, apoptosis induction, tumor cell invasion to name a few. There has been much-emerging evidence based on the versatility of flavonoids, their complex mechanism of action, lesser side effects, and varied pharmacological properties that make them potential anticancer agents. Challenges associated with their use in extraction, isolation, purification, and checking bioefficacy are also discussed.
\end{abstract}

Keywords: flavonoid; anticancer; chemoprotective; antioxidant; molecular mechanism; quercetin. (C) 2021 by the authors. This article is an open-access article distributed under the terms and conditions of the Creative Commons Attribution (CC BY) license (https://creativecommons.org/licenses/by/4.0/).

\section{Introduction}

In today's scenario, the emergence of cancer has become very prevalent in both urban and rural populations. A high rate of breast and cervix cancer has been diagnosed in women during prostate cancer and mouth cancer in men due to excessive use of tobacco-related products. There has been an established correlation between the fact that the consumption of the diet which is rich in fruits and vegetables leads to the reduction in the prevalence of healththreatening disorders, with polyphenols playing a part. Fruits, vegetables, tea, oils, and seeds are all good sources of polyphenols. Flavonoids are a diverse group of polyphenolic phytonutrients responsible for the origin of vivid colors in fruits and vegetables. Flavonoids are mostly present in large amounts in the genus Citrus and are mainly present in blue- and red-colored fruits and vegetables. Recommended Daily Allowance of flavonoid is based on clinical trials is $25-30 \mathrm{mg}$ per day to $100-130 \mathrm{mg}$ per day for therapeutic use [1]. The various classes of flavonoids based on their structure are flavonols, flavones, flavonones, flavanols, anthocyanidins, isoflavones, and chalcones catechins, flavans, dihydrochalcones, and bioflavonoids [2]. Dietary phenolic acids and flavonoids have immense potential to work as anticancer agents, which has been proved by various in vitro and in-vivo studies carried out by 
many groups of scientists worldwide. Among the flavonoids mainly Kaempferol, Resveratrol, Quercetin, Silibinin, Baicalein, Galangin, and Luteolin, have been identified in chemoprevention in hepatocellular carcinoma with preclinical and clinical evidence [3]. Their role in molecular mechanisms like induction of apoptosis, cell cycle arrest, downregulation of MMP-2 and MMP-9 enzyme activities, inhibition of cell proliferation, immunomodulatory effect, etc., are the key pathways targeting all phases of carcinogenesis [4-7]. To date, more than 10,000 flavonoids have been identified and categorized into different classes showing different activities. Along with anticancer effect, they also show antioxidant and anti inflammatory responses [8]. Among the other phenolic compounds, tannins also play an important role in chemoprotection [9]. Flavonoids studied from 22 plant families showed antimicrobial, antifungal, anti-edematogenic, anti-viral, anti-nociceptive, anti-histamine, and anti-ulcer properties [10].

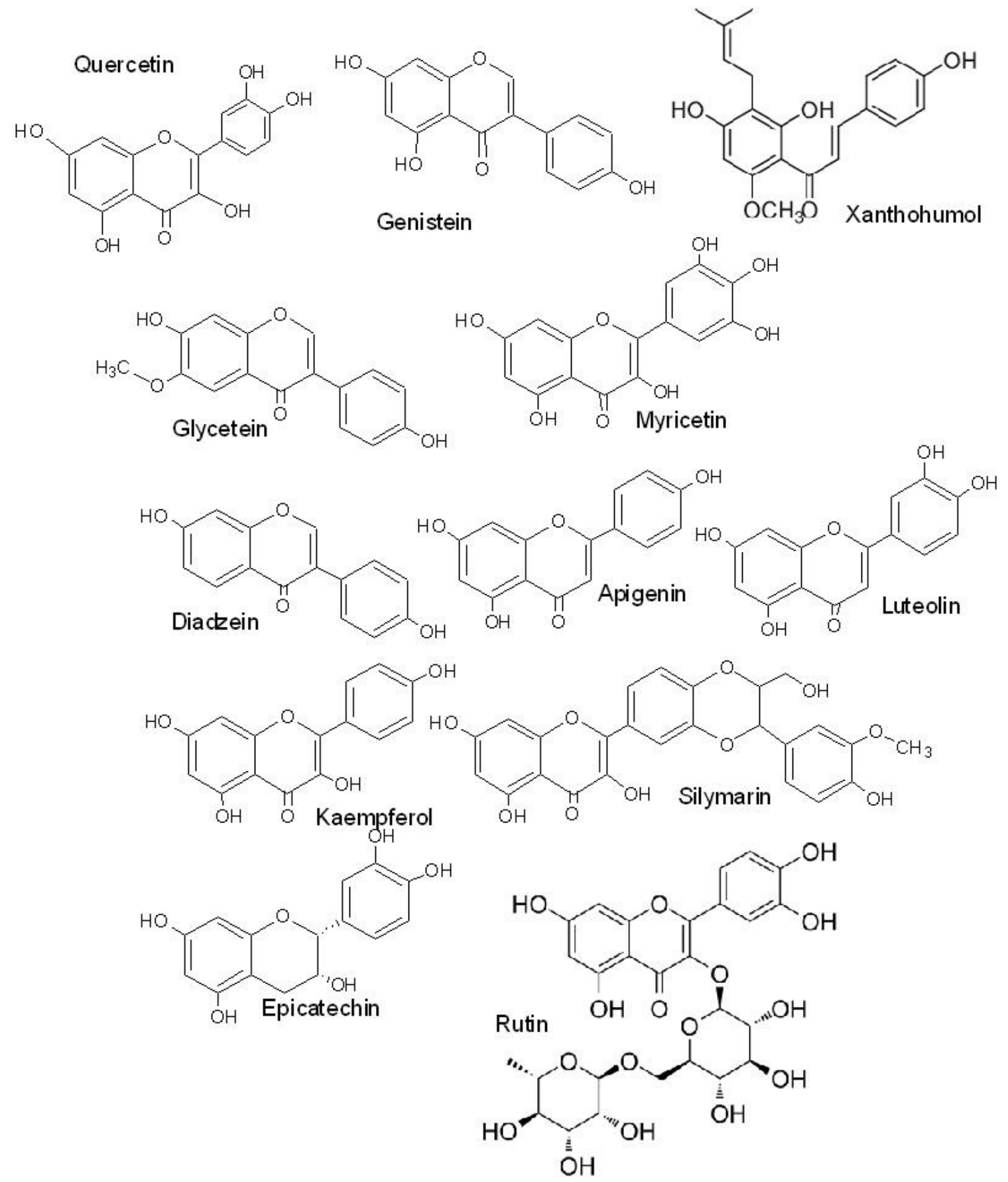

Figure 1. Structures of some important flavonoid compounds with anticancer potential [17,18]. 
Flavonoids have three characteristic ring systems having phenylated benzopyrone rings. The various structural features qualify flavonoids as an important class of compounds. The ring $\mathrm{B}$ of flavonoids having an ortho-dihydroxy (catechol) structure allows electron delocalization by the 2,3-double bond in conjugation in ring $\mathrm{C}$ with the 4-oxo function in it. The oxo group is hydrogen-bonded with the hydroxyl groups located at positions 3 (in-ring C) and 5 (in-ring A). ArO radical can react with another free radical or ROS to form a stable quinone structure indicating its antioxidant characteristics as depicted in Figure 2. The catechol moiety is responsible for the flavonoid's metal chelation activity. Therefore, when the hydroxylation pattern is studied of the ring $\mathrm{B}$, it basically has a significant impact on the action of specific flavones and flavonols, primarily for the inhibition of the protein kinase and the antiproliferation activity [17].

(a)<smiles>Cc1ccc(O)c(O)c1</smiles><smiles>CC1=CC(=O)C(=O)C=C1C(C)C(C)C(C)C</smiles>

(b)<smiles>O=c1cc(-c2ccccc2)oc2ccccc12</smiles>

Figure 2. (a) Antioxidant nature of polyphenols; (b) 2-phenyl-1,4-benzopyrone backbone of a flavonoid nucleus.

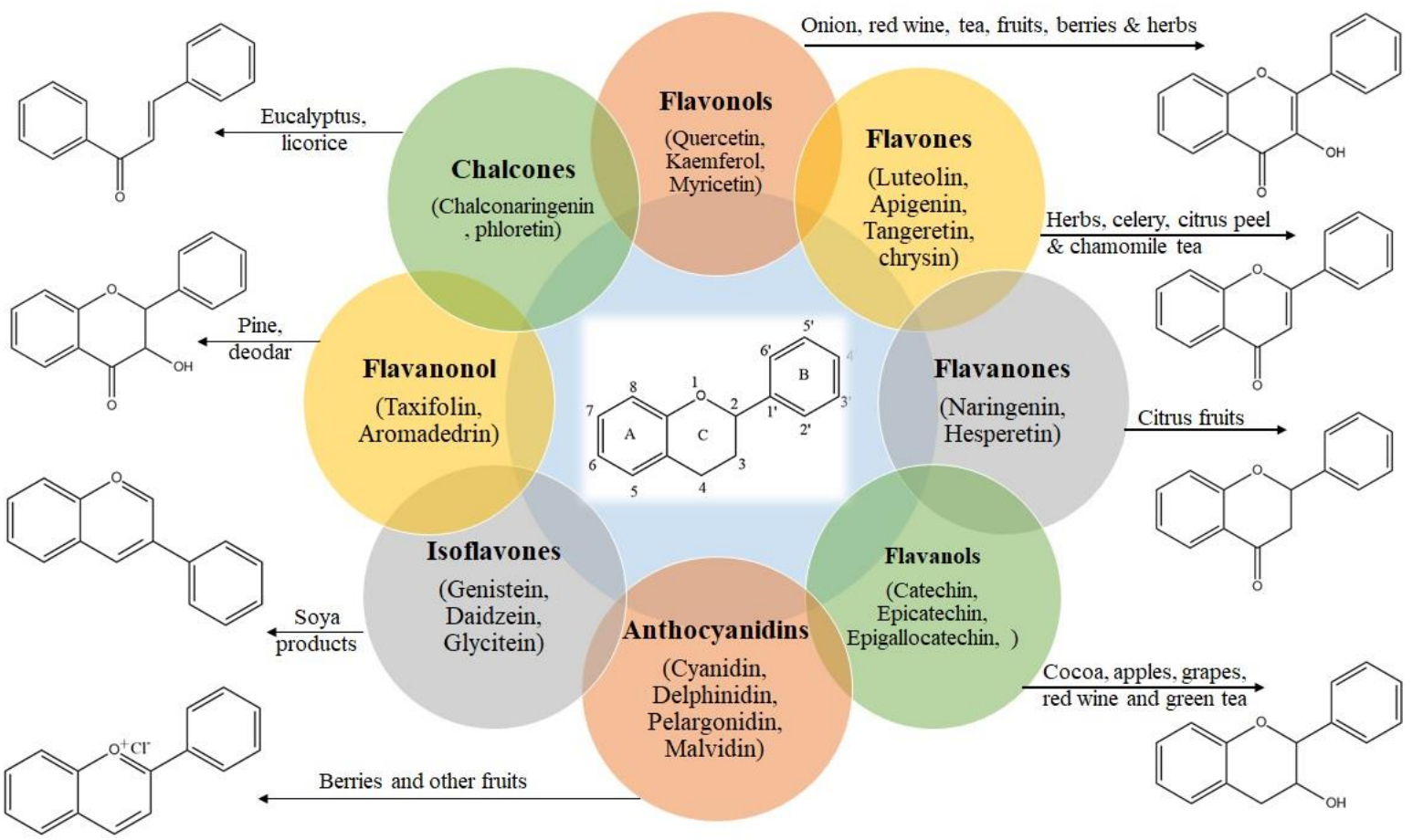

Figure 3. Dietary sources of flavonoids and distribution based on the structure in nature. 
Flavonoids have the potential to donate hydrogen atoms to carry out the reduction of the highly oxidizing free radicals, which include superoxide, hydroxyl alkoxyl, and peroxyl radicals [19]. Various numbers of the in vitro work have basically suggested apoptosis induction, kinase inhibition activity, suppression of the invasive behavior of the tumor, and suppression of matrix metalloproteinases cell growth inhibition as important pathways for some flavonoids that are able to act as anticancer agents [20]. There has been an increase in the association of the dietary flavonoids and cancer progression, making it important to investigate the mechanisms at a molecular level that are involved and qualify the flavonoids as potential anticancer agents.

\section{Flavonoids Biosynthesis}

The flavonoids are produced by carrying out the biosynthesis in plants by following the phenylpropanoid pathway and transforming phenylalanine to 4-coumaroyl CoA. The A ring is commonly derived from a molecule of phloroglucinol, or resorcinol which is generated through the acetate pathway. Also, it has a hydroxylation pattern that is distinct and is particularly observed at positions 5 and 7 in ring $\mathrm{A}$. The $\mathrm{B}$ ring is hydroxylated at 3, 4 or 3, 4, 5 positions derived from the shikimate pathway. The enzymes that have proven to be specific for the synthesis pathway of flavonoids basically include isomerases, chalcone synthase, dioxygenases, reductases, and hydroxylases. These enzymes basically modify the basic skeleton of the flavonoid that eventually produces numerous sub-classes and transferases, which change the backbone of the flavonoid along with methyl groups, sugars, and acyl moieties that regulates the physiological activity of the resultant flavonoid by affecting its reactivity, solubility, and interaction with cellular targets [21]. Flavones have been synthesized conventionally by condensing 2,4-dihydroxyacetophenone with aromatic aldehydes to obtain intermediate chalcones, which upon oxidative cyclization forms 7-hydroxy flavonoids [22]. Another approach produces an aryl ester by acylating o-hydroxyacetophenone with an aromatic acid chloride. The produced ester is then rearranged with the help of a base into a 1,3-diaryl1,3-diketone (the Baker-Venkataraman reaction) [23]. The latter molecule undergoes acidcatalyzed cyclization, yielding 2-arylchromone, which is a flavone.

In more recent approaches, the Suzuki-Miyaura reaction (1988) was applied for the synthesis of flavonoids, unnatural biflavonoids by using palladium $\left[\mathrm{Pd}\left(\mathrm{PPh}_{3}\right)_{4}\right]$ cross-coupling reactions using 3- halochromones and aryl boronic acid or esters. In a Heck coupling approach involving coupling between an unsaturated ketone and aryl iodide, flavonoid moiety can be obtained in a single step [24]. A novel microwave-assisted efficient, eco-friendly approach has shown excellent yield and shortened reaction time, requiring cheaper reagents involving modified Baker-Venkataraman rearrangement [25].

\section{Molecular Mechanisms for Chemoprotective Nature}

Carcinogenesis is a basically complicated multistep process comprising of three main stages [20]:

i) Initiation (rapid phase) - exposure, interaction and damage of DNA with carcinogenic agent.

ii) Promotion (relatively lengthy) - abnormal cells persist for a long period of time and replicate. 
iii) Progression (final phase) entails the transformation of premalignant cells to neoplastic cells with increased invasiveness, metastatic potential, and angiogenesis that develops new blood vessels in cancerous tissue. Figure 4 represents the various processes and factors that lead to tumor progression from initiation to form cancerous tissue.

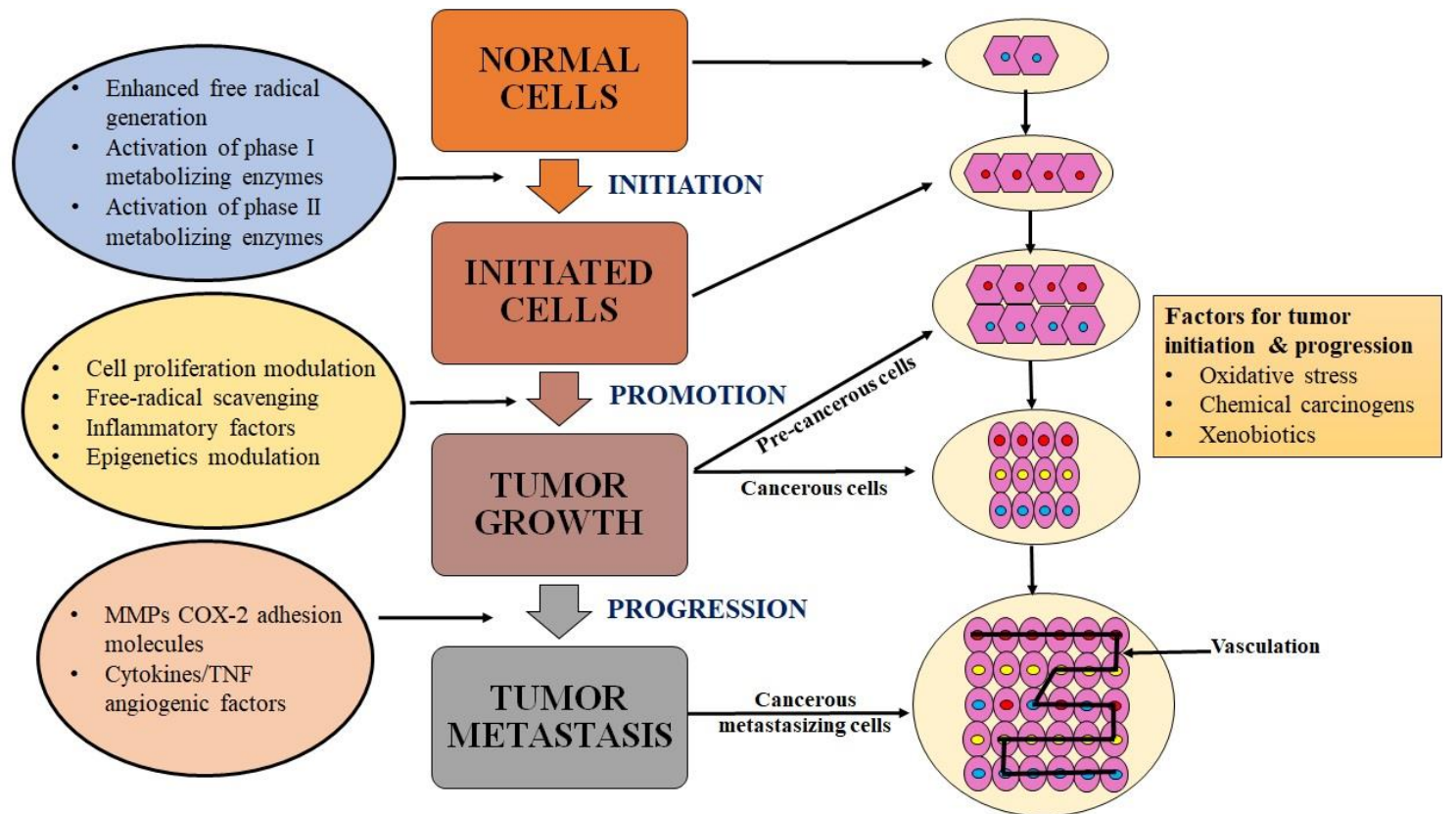

Figure 4. Schematic representation indicates the biological targets/processes that demonstrate the multistage process of initiation, promotion, and progression of carcinogenesis [recreated from reference [26].

Preventive measure for mutagenic effects includes the primary strategy against cancer. Cancer can be controlled in the early phases of carcinogenesis by various mechanisms, including control of signal transduction pathway, antioxidant mechanisms, hormones, angiogenesis inhibition, etc. Prevention of tumor invasiveness and the ability to spread is the most important strategy to treat cancer. There have been numerous modes of action found in the fight against tumor initiation. It mainly entails the inactivation of carcinogen, apoptosis induction, antioxidant effect, cell cycle arrest, angiogenesis inhibition, antiproliferation, multidrug resistance reversal, and combinatorial mechanisms [27]. Antioxidant activity is one of the important mechanisms contributing to the protective effects of flavonoids. Flavonoids (such as quercetin, genistein, and biochanin A) protect cells from reactive oxygen species by reducing Fenton-type reactions in the presence of $\mathrm{Fe}^{2+}$ ions through chelation. Flavonoids' prooxidant effects may be linked to cell signaling, in which flavonoids aid in the coordination of cell processes. The transmission of the growth factor signals to the nucleus is caused by a family of proteins called tyrosine kinases. They essentially compete with the catalytic domain of various oncogenic tyrosine kinase's ATP binding sites. Drugs that particularly suppress tyrosine kinase activity are considered potential anticancer agents because they do not have cytotoxic side effects like traditional chemotherapy. Inhibition of tyrosine kinase, inflammatory enzymes cyclooxygenase $(\mathrm{COX})$, and lipooxygenase by quercetin reduce inflammatory mediators such as prostaglandins and leukotrienes at cancer-related sites chronic inflammation [26]. Quercetin also induces cytoprotective autophagy. A group of flavonoid compounds having similarities with estrogen or phytoestrogen shows binding affinity towards $\mathrm{ER} \alpha$ and ER $\beta$ (the estrogen receptors present in the uterus and mammary glands, respectively). High exposure to estrogen is related to a greater risk for breast cancer [28]. Because quercetin's chemical structure, which includes a phenolic ring and a 2-hydroxy group, is relatable to 
estrogen and can bind to the estrogen receptors and regulate cell cycle progression. Certain other flavonoids like xanthohumol, ellagic acid, fisetin, apigenin, kaempferol, luteolin, morin, resveratrol have also shown inhibition of production of estrogen by modulation of estrogen receptors. Aromatase inhibition, anti-inflammatory mechanisms, antioxidant mechanisms, and anti-estrogenic processes can all be attributed to the polyphenol's powerful anticancer effect [29-34]. Aromatase is basically an estrogen synthase that is basically expressed in the tissue of breast cancer. Flavones such as luteolin and isoflavone have been shown to bind active sites of aromatase as estrogen receptors [35]. In carcinogenesis, an imbalance in the actions of cell cycle advancement proteins (Cyclins and cyclin-dependent kinases or CDK) and cell cycle arrest proteins (CDK inhibitors) causes significant cell proliferation. Several polyphenols and flavonoids have been used to cause cell cycle arrest and apoptosis in the $\mathrm{G}_{2} / \mathrm{M}$ phase, including quercetin, apigenin, resveratrol, and quercetin-3-methyl ether. Apoptosis (also called programmed cell death) is very important for carrying out many physiological processes, including homeostasis and further development. There are two types of apoptosis pathwaysintrinsic and extrinsic. Intrinsic apoptosis, which is mitochondrial type, is primarily regulated by $\mathrm{B}$ cell lymphoma family proteins, whereas the extrinsic pathway is triggered by the interaction of death receptors and their ligands. Many breast cancer cell lines mainly include the following; T47D, MCF-7, MDA-MB-453, and SK-BR-3 have been found to be inhibited through diverse mechanisms by quercetin, apigenin, resveratrol, genistein, and fisetin. It is observed that cancer stem cells develop multidrug resistance and resist chemotherapy leading to tumor recurrence. The overexpression of the transporter proteins that bind ATP serves as pumps and is required to reduce the intracellular drug concentration and is further connected to multidrug resistance. Polyphenols such as daidzein, silymarin, resveratrol, quercetin, naringenin, and hesperetin block the activity of these mentioned transporter proteins, which prevents drug efflux [36]. The cell cycle arrest, blocking of angiogenesis, induction of apoptosis, suppression of telomerase activity, and the inhibition of DNA topoisomerase II enzyme are the processes by which isoflavone, genistein, show anticancer properties. Certain novel synthetic flavonoids have specific methoxylated side-chain allow improved bioavailability and delivery to cancerous tissue. Flavone 8 -acetic acid (FAA) is found to be a new chemical structure that has undergone numerous clinical studies as an anticancer medication [37]. Another semisynthetic flavone flavopiridol inhibited cyclin-dependent kinases and displayed unique anticancer properties. Phase I and phase II trials have proven to be successful clinical trial against renal, prostate, colon and gastric carcinoma has used flavopiridol as a monotherapy [38].

Figure 5 describes the intrinsic and extrinsic apoptosis pathways and the genes involved in regulating them. Flavonoids also regulate proteins like breast cancer-resistant protein (BCRP), multidrug resistance proteins (MRP), and P-glycoprotein. The apoptosis is proceeded by two pathways: intrinsic pathway (mitochondria-mediated) as well as extrinsic pathway (death receptor-mediated). The extrinsic pathway is a receptor-driven pathway, whereas the intrinsic pathway is a stimuli-driven mitochondrion pathway. First, the extracellular ligands get attached to the transmembrane receptors' domain extracellularly. Both the pathways have their initiator caspases (cysteine-dependent aspartic directed proteases), which are caspases 2, 8, 9, and 10. These enhance proteolytic maturation by catalyzing the caspases of the effector. Executioner caspases 3, 6, and 7 cause the caspase cascade initiation and lead to cell demolition. Caspases play an important role in cell proliferation, tumor suppression, cell differentiation, and aging. Their deficiency can cause the induction of tumors. The damage of 
DNA initiates and speeds up apoptosis by undergoing the activation of protein $\mathrm{p} 53$, which is a tumor suppression protein. This step involves the transcription of the BAX (BCL2 Associated $\mathrm{X}$, Apoptosis Regulator) and BAK (BCL2 Antagonist), which also inhibits the transcription of BCL-2 and surviving, which are anti-apoptotic genes. There is a cytoplasmic interaction between the MCL-1 (Myeloid cell leukemia-1) and BCL-2 family proteins, which is antiapoptotic and p53. It takes place in the mitochondria, which involves the release of cytochromec from the outer membrane of the apoptosis. Also, p53 interacts directly with Bak/Bax by causing the activation by a mechanism which is commonly called "hit and run" that leads to the outer mitochondrial membrane permeabilization [39].

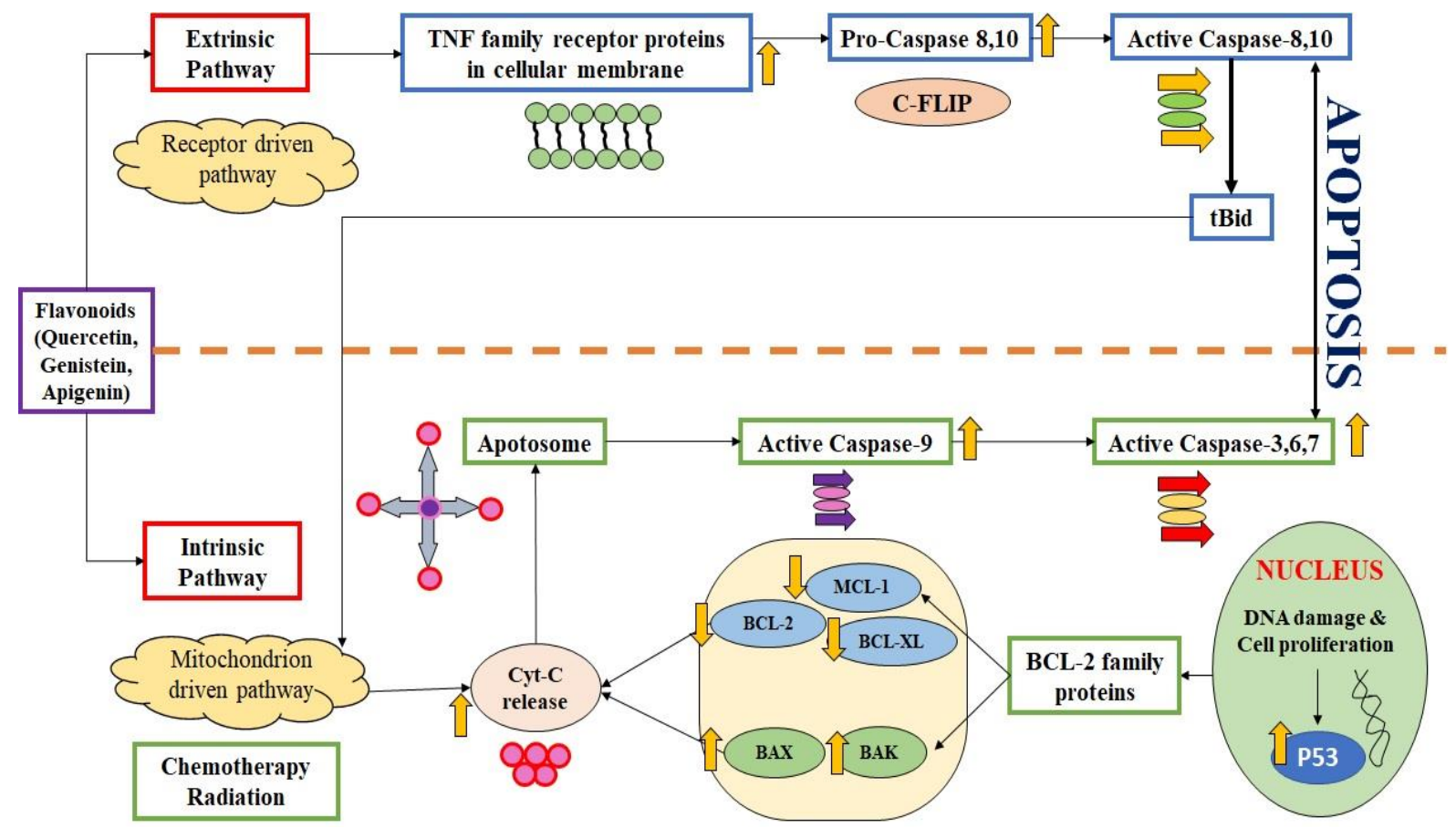

Figure 5. Intrinsic and extrinsic apoptosis pathways indicate the upregulation and downregulation of various genes involved.

The flavonoids have some effects on the process of initiation and promotion stages of the carcinogenicity as observed in vitro studies may be due to the following:

i) Kinase activity Inhibition (Quercetin as tested in human phase I trial)

ii) Induction of Apoptosis

iii) Matrix metalloproteinases suppression (MMPs)

iv) Tumour invasive behavior suppression

The anti-cancerous activity of flavonoids over various human/mouse cancer cell lines is tabulated in Table 1. Anticancer activity can be verified by various in-vivo studies following molecular mechanisms mentioned below:

i) Downregulation of mutated p53 gene producing protein (its accumulation caused the initiation of cancer) causing cell cycle arrest at G2-M phase

ii) Tyrosine kinase inhibition

iii) Antiproliferation

iv) Inhibition of protein tyrosine $\&$ focal adhesion kinase, the transduction of signal from enzymes taking place from the cell surface

v) Inhibition of tumor pathways of angiogenesis

vi) Inhibition of proteins protecting from heat shocks 
vii) Inhibition of expression of RAS oncogenic proteins used for cancer cell growth and differentiation

Table 1. Role of flavonoids studied in vitro on various cancer cell lines from reference [40].

\begin{tabular}{|c|c|c|c|c|}
\hline $\begin{array}{l}\text { Human } \\
\text { Cancer }\end{array}$ & Cell line & Flavonoid & Action & References \\
\hline Oral & $\begin{array}{l}\mathrm{SCC}-25 \\
\mathrm{HSC}-2 \\
\mathrm{HSG} \\
\end{array}$ & $\begin{array}{c}\text { Flavanones, isoflavans, chalcones, } \\
\text { genistein, quercetin }\end{array}$ & $\begin{array}{c}\text { Antiproliferative \& } \\
\text { decreases polyamine level, } \\
\text { induction of apoptosis }\end{array}$ & [41-44] \\
\hline Breast & MCF-7 & $\begin{array}{c}\text { Genistein, Flavanones, daidzein, } \\
\text { luteolin, quercetin }\end{array}$ & Antiproliferative & {$[45,46]$} \\
\hline Thyroid & $\begin{array}{l}\text { WRO, } \\
\text { NPA, } \\
\text { ARO }\end{array}$ & $\begin{array}{l}\text { Chrystin, biochanin A, Apigenin } \\
\text { kaempferol, genistein, luteolin }\end{array}$ & Antiproliferative & {$[47,48]$} \\
\hline Lung & $\begin{array}{l}\text { SW900, SK- } \\
\text { LU1, A549, } \\
\text { H441, H661 }\end{array}$ & Flavone, quercetin, catechin & $\begin{array}{c}\text { Cytotoxic, suppression of } \\
\text { tumour invasion and } \\
\text { metastasis }\end{array}$ & {$[49,50]$} \\
\hline Prostrate & $\begin{array}{c}\text { DU145, } \\
\text { LNCaP, PC3 }\end{array}$ & $\begin{array}{l}\text { Quercetin, catechin, apigenin, } \\
\text { kaempferol, myricetin, } \\
\text { epigallocatechin-3-gallate, } \\
\text { silymarin, genistein, luteolin }\end{array}$ & $\begin{array}{l}\text { Inhibition to synthetase } \\
\text { activity of fatty acid and } \\
\text { lipogenesis }\end{array}$ & [51-53] \\
\hline Colon & $\begin{array}{c}\text { HCT-15, } \\
\text { Caco-2, IEC- } \\
6, \text { HT-29 } \\
\end{array}$ & $\begin{array}{c}\text { Genistein, Flavone, anthocyanin, } \\
\text { quercetin }\end{array}$ & Antiproliferative & [54-56] \\
\hline Leukemia & $\begin{array}{c}\text { K562, HL- } \\
60, \text { Jurat }\end{array}$ & $\begin{array}{c}\text { Genistein, Apigenin, chalcones, } \\
\text { myricetin, quercetin }\end{array}$ & Antiproliferative & [49] \\
\hline $\begin{array}{c}\text { Mouse } \\
\text { Melanoma }\end{array}$ & $\begin{array}{l}\text { B16-BL6, } \\
\text { 4A5 }\end{array}$ & Chalcone & $\begin{array}{l}\text { Phosphorylation and } \\
\text { inhibition of mitogen- } \\
\text { activated protein kinase }\end{array}$ & [57] \\
\hline
\end{tabular}

\section{Quercetin - the Most Important Anticancer Flavonoid}

Quercetin is thought to cause mitochondrial death and G2/M cell cycle arrest in proliferating lymphoid cells via a p53-dependent mechanism. In vitro studies on P-388 leukemia cells, human breast cancer cells, gastric cancer cells (HGC-27, NUGC-2, NKN-7, and MKN-28), human squamous, colon cancer cells (COLON 320 DM), ovarian cancer cells, and gliosarcoma cells (CNS tumor cells) found quercetin to inhibit the growth of a variety of aggressive tumor cell lines [58]. The reduction of tumor cell growth by quercetin is thought to be because of its interaction with nuclear type II estrogen binding sites (EBS). Furthermore, an experimental model of quercetin verified its antiproliferative action by inhibition in signal transduction in human breast cancer cells. The phase I and phase II clinical studies on humans with intravenous doses ranging from $60 \mathrm{mg} / \mathrm{m}^{2}$ to $1700 \mathrm{mg} / \mathrm{m}^{2}$ were proven effective against ovarian cancer patients studied during three weeks [59].

\section{Challenges faced in using Flavonoids as Anticancer Agents}

Flavonoids are basically one of the most important polyphenols. These can be found mainly in fruits, chocolates, vegetables, and many plant sources. Flavonoids have proven to have some anticancer efficacy without any major side effects, and, as a result, these are used in the development of many medicinal drugs. But some challenges are faced in the extraction of the flavonoids when extracted from their original plant sources. If there is a continuous extraction of flavonoids from their plant sources, extinction is possible. As a result, the whole biodiversity gets disrupted. A multistep is followed for the extraction of the flavonoids as it first involves its identification, isolation, and then purification. To carry out the procedure, a combination is used of several technologies just for the preliminary steps. The steps include 
column chromatography, solvent extraction, high-performance liquid chromatography (HPLC), etc. Despite their enormous pharmacological values, there are still certain challenges to overcome, like low bioavailability limits due to their low permeability and lower solubility in the gastrointestinal tract. Also, their glycosylated form may get hydrolyzed under acidic $\mathrm{pH}$ in the stomach. For this, microencapsulation by biocompatible coating polymers approach has been suggested as scientific advancement [60]. The accurate results and the implementation of these set of procedures are very time-consuming and have a high-cost involvement. Also, the yield obtained by such processes is very low and not up to the desired value. The most important factor that restricts the pathway of flavonoid extraction is the biosynthetic pathway. It basically results in the variable composition of the flavonoid that occurs at the different stages of the growth of a plant and is followed by a different set of environmental conditions. If there is a variation in the flavonoid composition, the flavonoid yield's predictability gradually decreases. As a result, an inconsistency in the data could be observed after every extraction. Another limitation that could be recorded is that the flavonoids are labile because of a high level of degradation, and alteration could be recorded in their chemical structures, which ultimately results in the loss of the activity during the process of purification.

There may be certain biological challenges that may be faced for flavonoids absorption. As the oral administration of the flavonoids is followed, there is a possibility that a significant degradation in their activity by microflora and enterohepatic circulation depends on the compound used. The most common and abundant microbiome that is observed in human beings is colonic microflora. These microorganisms could show the biotransformation of certain drugs to metabolites that tend to alter their efficacies and toxicities. They can even reduce cholesterol absorption and even increase the rate of mucus secretion in the gut. Their role in the bioavailability of flavonoids remains completely ineffective. They even tend to bio-transform to the small phenolic groups having similar effects. The flavonoids like apigenin, kaempferol, genistein, and naringenin are more prone to degradation caused by the microflora, resulting in lower bioavailability.

Certain environmental factors like temperature, UV radiation, oxygen exposure, $\mathrm{pH}$, etc., have proven to reduce the stability of the flavonoids and may even cause their degradation to occur. The most important factor that could get optimized during the process of extraction, purification, and storage of flavonoids is temperature. Light can also alter the biosynthesis as well as the biochemical activities of flavonoids. The interaction of fiber with dietary flavonoids affects the absorption process of flavonoids. This occurs in a way that the dietary fiber forms the complex with flavonoids by trapping it in their matrix. It enhances the gastric viscosity of the fluid, decreasing the absorption property of flavonoids.

We can overcome these challenges by optimizing the isolation and purification methods to increase the yield of flavonoids production. The method that was incorporated for the optimization is RSM which is known as the response surface methodology. Also, by the use of high speed and counter-current chromatography, the cost could be reduced, and a higher yield can be obtained. The other technology that can be incorporated and is widely emerging is nanoharvesting. The nanoparticles are used to harvest flavonoids as they can easily bind those compounds considered a target and can even carry out the cells without harming the plants.

As mentioned earlier, the extraction of certain compounds from the original plant source can cause harm to the plant commodities directly. So, microbe production of natural products like flavonoids is considered an attractive approach. This approach has the advantage 
as it preserves the environmental resources and the economic stocks. Moreover, it consumes the minimum amount of energy, and waste emission is negligible [59].

\section{Conclusions}

Flavonoids have a significant impact on the immunological events that occur during the genesis and progression of cancer. Flavonoids and important enzymes linked to neoplastic cells and metastasis interact, providing fresh information for cancer researchers. The two signalingrelated pathways, apoptosis, and autophagy are altered by polyphenol therapy as per recent studies with proven experimental evidence. There is a fine balance between pro-and antioxidant properties exhibited by flavonoids which involve a complex mechanism of action [61]. Lotha and Kavitha et al. have recommended positive associations with the dietary flavonoid intake and anticancer impact on human health $[39,62,63]$. In vitro studies have efficiently proved flavonoids to be cell growth and kinase activity inhibitor, antioxidant, apoptotic inducer, suppressor of matrix metalloproteinases, tumor invasive behavior, and cause reversal of multidrug resistance (limitation of chemotherapy). In vivo studies have shown that using flavonoids in a desirable amount reduces inflammation, inhibits proliferation, increases latency, and reduces tumor growth and spread. The experimental studies and increasing knowledge about flavonoids' mechanisms of action and the structure-activity relationship (SAR) have resulted in intriguing new research rationales for cancer prevention. The various molecular mechanisms discussed in this review arising due to structure-activity relationships and In vivo studies lead to a promising outcome presenting flavonoids as effective anticancer agents.

\section{Funding}

The authors have received no funding to carry out this work.

\section{Acknowledgments}

The authors would like to thank Amity University Uttar Pradesh for providing the necessary library facilities and infrastructure for carrying out this work.

\section{Conflicts of Interest}

The authors declare no conflict of interest.

\section{References}

1. Chun, O.K.; Chung, S.J.; Song, W.O. Estimated Dietary Flavonoid Intake and Major Food Sources of U.S. Adults. The Journal of Nutrition 2007, 137, 1244-1252, https://doi.org/10.1093/jn/137.5.1244.

2. Panche, A.N.; Diwan, A.D.; Chandra, S.R. Flavonoids: an overview. Journal of Nutritional Science 2016, 5, e47, https://doi.org/10.1017/jns.2016.41.

3. Kumar, P.; Dixit, J.; Saini, R.; Verma, P.; Mishra, A.K.; NathTiwari, K. Potential of Flavonoids as Anticancer Drugs. Phytopharmaceuticals: Potential Therapeutic Applications 2021, 135-159, https://doi.org/10.1002/9781119682059.ch7.

4. Bonta, R.K. Dietary phenolic acids and flavonoids as potential anticancer agents: Current state of the art and future perspectives. Anticancer Agents in Medicinal Chemistry (Formerly Current Medicinal Chemistry-AntiCancer Agents) 2020, 20, 29-48, https://doi.org/10.2174/1871520619666191019112712.

5. Liskova, A.; Samec, M.; Koklesova, L.; Brockmueller, A.; Zhai, K.; Abdellatif, B.; Siddiqui, M.; Biringer, K.; Kudela, E.; Pec, M.; Gadanec, K.; Šudomová, M.; Hassan, S.T.S.; Zulli, A.; Shakibaei, M.; Giordano, F.A.; Büsselberg, D.; Golubnitschaja, O.; Kubatka, P. Flavonoids as an effective sensitizer for anticancer 
therapy: insights into multi-faceted mechanisms and applicability towards individualized patient profiles. EPMA Journal 2021, 12, 155-176, https://doi.org/10.1007/s13167-021-00242-5.

6. Liskova, A.; Koklesova, L.; Samec, M.; Smejkal, K.; Samuel, S.M.; Varghese, E.; Abotaleb, M.; Biringer, K.; Kudela, E.; Danko, J.; Shakibaei, M.; Kwon, T.K.; Büsselberg, D.; Kubatka, P. Flavonoids in Cancer Metastasis. Cancers 2020, 12, 1498, https://doi.org/10.3390/cancers12061498.

7. Tomko, A.M.; Whynot, E.G.; Ellis, L.D.; Dupré, D.J. Anti-Cancer Potential of Cannabinoids, Terpenes, and Flavonoids Present in Cannabis. Cancers 2020, 12, 1985, https://doi.org/10.3390/cancers12071985.

8. Hosseinzadeh, E.; Hassanzadeh, A.; Marofi, F.; Alivand, M.R.; Solali, S. Flavonoid-based cancer therapy: an updated review. Anticancer Agents in Medicinal Chemistry (Formerly Current Medicinal Chemistry-AntiCancer Agents) 2020, 20, 1398-1414, https://doi.org/10.2174/1871520620666200423071759.

9. Teodor, E.D.; Ungureanu, O.; Gatea, F.; Radu, G.L. The Potential of Flavonoids and Tannins from Medicinal Plants as Anticancer Agents. Anticancer Agents in Medicinal Chemistry (Formerly Current Medicinal $\begin{array}{llll}\text { Chemistry-Anti-Cancer } & \text { Agents) } & \text { 2020, 2216-2227, }\end{array}$ https://doi.org/10.2174/1871520620666200516150829.

10. Ekalu, A.; Habila, J.D. Flavonoids: isolation, characterization, and health benefits. Beni-Suef University Journal of Basic and Applied Sciences 2020, 9, 45, https://doi.org/10.1186/s43088-020-00065-9.

11. Godinho, P.I.C.; Soengas, R.G.; Silva, V.L.M. Therapeutic Potential of Glycosyl Flavonoids as AntiCoronaviral Agents. Pharmaceuticals 2021, 14, 546, https://doi.org/10.3390/ph14060546.

12. Ganai, S.A.; Sheikh, F.A.; Baba, Z.A.; Mir, M.A.; Mantoo, M.A.; Yatoo, M.A. Anticancer activity of the plant flavonoid luteolin against preclinical models of various cancers and insights on different signalling mechanisms modulated. Phytotherapy Research 2021, https://doi.org/10.1002/ptr.7044.

13. Wang, X.; Chen, B.; Xu, D.; Li, Z.; Liu, H.; Huang, Z.; Huang, K.; Lin, X.; Yao, H. Molecular mechanism and pharmacokinetics of flavonoids in the treatment of resistant EGF receptor-mutated non-small-cell lung cancer: A narrative review. British Journal of Pharmacology 2021, 178, 1388-1406, https://doi.org/10.1111/bph.15360.

14. Ezzati, M.; Yousefi, B.; Velaei, K.; Safa, A. A review on anticancer properties of Quercetin in breast cancer. Life Sciences 2020, 248, 117463, https://doi.org/10.1016/j.lfs.2020.117463.

15. Anwar, S.S.; Al-Shmgani, H.S.A.; Tawfeeq, A.T.; Sulaiman, G.M.; Al-Mousawi, Y.H. In silico analysis of quercetin as potential anticancer agents. Materials Today: Proceedings 2021, 42, 2521-2526, https://doi.org/10.1016/j.matpr.2020.12.573.

16. Stevens, J.F.; Page, J.E. Xanthohumol and related prenylflavonoids from hops and beer: to your good health! Phytochemistry 2004, 65, 1317-1330, https://doi.org/10.1016/j.phytochem.2004.04.025.

17. Martinez-Perez, C.; Ward, C.; Cook, G.; Mullen, P.; McPhail, D.; Harrison, D. J.; Langdon, S.P. Novel flavonoids as anticancer agents: mechanisms of action and promise for their potential application in breast cancer. Biochemical Society Transactions 2014, 42, 1017-1023, https://doi.org/10.1042/bst20140073.

18. Kanadaswami, C.; Lee, L.-T.; Lee, P.-P.H.; Hwang, J.-J.; Ke, F.-C.; Huang, Y.-T.; Lee, M.-T. The antitumor activities of flavonoids. In vivo 2005, 19, 895-909, https://iv.iiarjournals.org/content/19/5/895.short.

19. Kumar, S.; Pandey, A.K. Chemistry and Biological Activities of Flavonoids: An Overview. The Scientific World Journal 2013, 2013, 162750, https://doi.org/10.1155/2013/162750.

20. Batra, P.; Sharma, A.K. Anti-cancer potential of flavonoids: recent trends and future perspectives. 3 Biotech 2013, 3, 439-459, https://doi.org/10.1007/s13205-013-0117-5.

21. Falcone Ferreyra, M.L.; Rius, S.; Casati, P. Flavonoids: biosynthesis, biological functions, and biotechnological applications. Frontiers in Plant Science 2012, 3, https://doi.org/10.3389/fpls.2012.00222.

22. Patel, S.; Shah, U. Synthesis of flavones from 2-hydroxy acetophenone and aromatic aldehyde derivatives by conventional methods and green chemistry approach. Synthesis 2017, 10, 403-306, http://dx.doi.org/10.22159/ajpcr.2017.v10i2.15928.

23. Ameen, D.; Snape, T.J. Mechanism and application of Baker-Venkataraman $\mathrm{O} \rightarrow \mathrm{C}$ acyl migration reactions. Synthesis 2015, 47, 141-158, https://doi.org/10.1055/s-0034-1379498.

24. Selepe, M.A.; Van Heerden, F.R. Application of the Suzuki-Miyaura reaction in the synthesis of flavonoids. Molecules 2013, 18, 4739-4765, https://doi.org/10.3390/molecules18044739.

25. Ghani, S.B.A.; Weaver, L.; Zidan, Z.H.; Ali, H.M.; Keevil, C.W.; Brown, R.C. Microwave-assisted synthesis and antimicrobial activities of flavonoid derivatives. Bioorganic \& medicinal chemistry letters 2008, 18, 518522, https://doi.org/10.1016/j.bmcl.2007.11.081.

26. Abdal Dayem, A.; Choi, H.Y.; Yang, G.-M.; Kim, K.; Saha, S.K.; Cho, S.-G. The Anti-Cancer Effect of Polyphenols against Breast Cancer and Cancer Stem Cells: Molecular Mechanisms. Nutrients 2016, 8, 581, https://doi.org/10.3390/nu8090581.

27. Chahar, M.K.; Sharma, N.; Dobhal, M.P.; Joshi, Y.C. Flavonoids: A versatile source of anticancer drugs. Pharmacognosy reviews 2011, 5, 1-12, https://doi.org/10.4103/0973-7847.79093.

28. Adlercreutz, H. Phyto-oestrogens and cancer. The lancet oncology 2002, 3, 364-373, https://doi.org/10.1016/S1470-2045(02)00777-5.

29. Quideau, S.; Deffieux, D.; Douat-Casassus, C.; Pouységu, L. Plant polyphenols: chemical properties, biological activities, and synthesis. Angewandte Chemie International Edition 2011, 50, 586-621, https://doi.org/10.1002/anie.201000044. 
30. Scalbert, A.; Manach, C.; Morand, C.; Rémésy, C.; L, J.; Jiménez, L. Dietary polyphenols and the prevention of diseases. Crit Rev Food Sci Nutr 2005, 45, 287-306, https://doi.org/10.1080/1040869059096.

31. García-Lafuente, A.; Guillamón, E.; Villares, A.; Rostagno, M.A.; Martínez, J.A. Flavonoids as antiinflammatory agents: implications in cancer and cardiovascular disease. Inflammation Research 2009, 58, 537-552, https://doi.org/10.1007/s00011-009-0037-3.

32. Thomasset, S.C.; Berry, D.P.; Garcea, G.; Marczylo, T.; Steward, W.P.; Gescher, A.J. Dietary polyphenolic phytochemicals - promising cancer chemopreventive agents in humans? A review of their clinical properties. International journal of cancer 2007, 120, 451-458, https://doi.org/10.1002/ijc.22419.

33. Barnes, S.; Prasain, J.; D'Alessandro, T.; Arabshahi, A.; Botting, N.; Lila, M.A.; Jackson, G.; Janle, E.M.; Weaver, C.M. The metabolism and analysis of isoflavones and other dietary polyphenols in foods and biological systems. Food \& function 2011, 2, 235-244, https://doi.org/10.1039/C1FO10025D.

34. Kao, Y.-C.; Zhou, C.; Sherman, M.; Laughton, C.A.; Chen, S. Molecular basis of the inhibition of human aromatase (estrogen synthetase) by flavone and isoflavone phytoestrogens: A site-directed mutagenesis study. Environmental health perspectives 1998, 106, 85-92, https://doi.org/10.1289/ehp.9810685.

35. Wu, C.P.; Calcagno, A.M.; Hladky, S.B.; Ambudkar, S.V.; Barrand, M.A. Modulatory effects of plant phenols on human multidrug-resistance proteins 1, 4 and 5 (ABCC1, 4 and 5). The FEBS journal 2005, 272, 4725-4740, https://doi.org/10.1111/j.1742-4658.2005.04888.x.

36. Cummings, J.; Smyth, J.F. Flavone 8-acetic acid: our current understanding of its mechanism of action in solid tumours. Cancer chemotherapy and pharmacology 1989, 24, 269-272, https://doi.org/10.1007/BF00304756.

37. Wang, H. Flavopiridol. National Cancer Institute. Current opinion in investigational drugs (London, England: 2000) 2001, 2, 1149-1155.

38. Fukai, T.; Sakagami, H.; Toguchi, M.; Takayama, F.; Iwakura, I.; Atsumi, T.; Ueha, T.; Nakashima, H.; Nomura, T. Cytotoxic activity of low molecular weight polyphenols against human oral tumor cell lines. Anticancer research 2000, 20, 2525-2536.

39. Goldar, S.; Khaniani, M.S.; Derakhshan, S.M.; Baradaran, B. Molecular mechanisms of apoptosis and roles in cancer development and treatment. Asian Pacific Journal of Cancer Prevention 2015, 16, 2129-2144, https://doi.org/10.7314/APJCP.2015.16.6.2129.

40. Ren, W.; Qiao, Z.; Wang, H.; Zhu, L.; Zhang, L. Flavonoids: promising anticancer agents. Medicinal research reviews 2003, 23, 519-534, https://doi.org/10.1002/med.10033.

41. Sakagami, H.; Jiang, Y.; Kusama, K.; Atsumi, T.; Ueha, T.; Toguchi, M.; Iwakura, I.; Satoh, K.; Fukai, T.; Nomura, T. Induction of apoptosis by flavones, flavonols (3-hydroxyflavones) and isoprenoid-substituted flavonoids in human oral tumor cell lines. Anticancer research 2000, 20, 271-277.

42. Elattar, T.; Virji, A. The inhibitory effect of curcumin, genistein, quercetin and cisplatin on the growth of oral cancer cells in vitro. Anticancer research 2000, 20, 1733-1738.

43. Elattar, T.; Virji, A.S. Effect of tea polyphenols on growth of oral squamous carcinoma cells in vitro. Anticancer research 2000, 20, 3459-3465.

44. Pouget, C.; Lauthier, F.; Simon, A.; Fagnere, C.; Basly, J.-P.; Delage, C.; Chulia, A.-J. Flavonoids: structural requirements for antiproliferative activity on breast cancer cells. Bioorganic \& medicinal chemistry letters 2001, 11, 3095-3097, https://doi.org/10.1016/S0960-894X(01)00617-5.

45. Han, D.-H.; Tachibana, H.; Yamada, K. Inhibition of environmental estrogen-induced proliferation of human breast carcinoma MCF-7 cells by flavonoids. In vitro Cellular \& Developmental Biology - Animal 2001, 37, 275, https://doi.org/10.1007/bf02577543.

46. Yin, F.; Giuliano, A.; Van Herle, A. Signal pathways involved in apigenin inhibition of growth and induction of apoptosis of human anaplastic thyroid cancer cells (ARO). Anticancer research 1999, 19, 4297-4303, PMID: 10628390.

47. Yin, F.; Giuliano, A.E.; Van Herle, A.J. Growth inhibitory effects of flavonoids in human thyroid cancer cell lines. Thyroid 1999, 9, 369-376, https://doi.org/10.1089/thy.1999.9.369.

48. Bai, F.; Matsui, T.; Ohtani-Fujita, N.; Matsukawa, Y.; Ding, Y.; Sakai, T. Promoter activation and following induction of the p21/WAF1 gene by flavone is involved in G1 phase arrest in A549 lung adenocarcinoma cells. FEBS letters 1998, 437, 61-64, https://doi.org/10.1016/S0014-5793(98)01198-3.

49. Caltagirone, S.; Ranelletti, F.O.; Rinelli, A.; Maggiano, N.; Colasante, A.; Musiani, P.; Aiello, F.B.; Piantelli, M. Interaction with type II estrogen binding sites and antiproliferative activity of tamoxifen and quercetin in human non-small-cell lung cancer. American Journal of Respiratory Cell and Molecular Biology 1997, 17, 51-59, https://doi.org/10.1165/ajrcmb.17.1.2728.

50. Bhatia, N.; Agarwal, R. Detrimental effect of cancer preventive phytochemicals silymarin, genistein and epigallocatechin 3-gallate on epigenetic events in human prostate carcinoma DU145 cells. The Prostate 2001, 46, 98-107, https://doi.org/10.1002/1097-0045(20010201)46:2<98::AID-PROS1013>3.0.CO;2-K.

51. Kampa, M.; Hatzoglou, A.; Notas, G.; Damianaki, A.; Bakogeorgou, E.; Gemetzi, C.; Kouroumalis, E.; Martin, P.-M.; Castanas, E. Wine antioxidant polyphenols inhibit the proliferation of human prostate cancer cell lines. Nutrition and cancer 2000, 37, 223-233, https://doi.org/10.1207/S15327914NC372_16. 
52. Agarwal, R. Cell signaling and regulators of cell cycle as molecular targets for prostate cancer prevention by dietary agents. Biochemical pharmacology 2000, 60, 1051-1059, https://doi.org/10.1016/S00062952(00)00385-3.

53. Wenzel, U.; Kuntz, S.; Brendel, M.D.; Daniel, H. Dietary flavone is a potent apoptosis inducer in human colon carcinoma cells. Cancer research 2000, 60, 3823-3831.

54. Kuntz, S.; Wenzel, U.; Daniel, H. Comparative analysis of the effects of flavonoids on proliferation, cytotoxicity, and apoptosis in human colon cancer cell lines. European journal of nutrition 1999, 38, 133142, https://doi.org/10.1007/s003940050054.

55. Kuo, S.-M.; Morehouse Jr, H.F.; Lin, C.-P. Effect of antiproliferative flavonoids on ascorbic acid accumulation in human colon adenocarcinoma cells. Cancer letters 1997, 116, 131-137, https://doi.org/10.1016/S0304-3835(97)00183-3.

56. Wang, I.K.; Lin-Shiau, S.Y.; Lin, J.K. Induction of apoptosis by apigenin and related flavonoids through cytochrome c release and activation of caspase-9 and caspase-3 in leukaemia HL-60 cells. European Journal of Cancer 1999, 35, 1517-1525, https://doi.org/10.1016/S0959-8049(99)00168-9.

57. Iwashita, K.; Kobori, M.; Yamaki, K.; Tsushida, T. Flavonoids inhibit cell growth and induce apoptosis in B16 melanoma 4A5 cells. Bioscience, biotechnology, and biochemistry 2000, 64, 1813-1820, https://doi.org/10.1271/bbb.64.1813.

58. Ferry, D.R.; Smith, A.; Malkhandi, J.; Fyfe, D.W.; deTakats, P.G.; Anderson, D.; Baker, J.; Kerr, D.J. Phase I clinical trial of the flavonoid quercetin: pharmacokinetics and evidence for In vivo tyrosine kinase inhibition. Clinical cancer research 1996, 2, 659-668.

59. Amawi, H.; Ashby, C.R.; Tiwari, A.K. Cancer chemoprevention through dietary flavonoids: what's limiting? Chinese journal of cancer 2017, 36, 1-13, https://doi.org/10.1186/s40880-017-0217-4.

60. Teng, H.; Zheng, Y.; Cao, H.; Huang, Q.; Xiao, J.; Chen, L. Enhancement of bioavailability and bioactivity of diet-derived flavonoids by application of nanotechnology: a review. Critical Reviews in Food Science and Nutrition 2021, 1-16, https://doi.org/10.1080/10408398.2021.1947772.

61. Ramadhan, F.; Mukarramah, L.; Oktavia, F.A.R.H.; Yulian, R.; Annisyah, N.H.; Asyiah, I.N. Flavonoids from endophytic bacteria of cosmos caudatus Kunth. Leaf as anticancer and antimicrobial. Asian Journal of Pharmaceutical and Clinical Research 2000-204, http://dx.doi.org/10.22159/ajpcr.2018.v11i1.21987.

62. Lotha, R.; Sivasubramanian, A. Flavonoids nutraceuticals in prevention and treatment of cancer: A review. Asian Journal of Pharmaceutical and Clinical Research 2018, 11, 42-47, https://doi.org/10.22159/ajpcr.2018.v11i1.23410.

63. Kavitha, K. Evaluation of total phenols, total flavonoids, antioxidant, and anticancer activity of Mucuna pruriens seed extract. Asian Journal of Pharmaceutical and Clinical Research 2018, 11, 242-246, https://doi.org/10.22159/ajpcr.2018.v11i3.22999. 